\title{
Cytotoxic chemotherapeutic management of newly diagnosed glioblastoma multiforme
}

\author{
Camilo E. Fadul $\cdot$ Patrick Y. Wen • \\ Lyndon Kim · Jeffrey J. Olson
}

Published online: 8 January 2009

(C) Springer Science+Business Media, LLC. 2009

Erratum to: J Neurooncol (2008) 89:339-357

DOI 10.1007/s11060-008-9615-4

In Table 3 (p. 353) of the original publication, survival data for the glioblastoma subgroups of the Westphal et al. (Neuro Oncol, 2003) and Valtonen et al. (Neurosurgery, 1997) studies refer to "mean" survival. These data are actually "median" survival. In the text, the data are correctly presented as "median" survival (see p. 352 of the original publication).

The online version of the original article can be found under doi:10.1007/s11060-008-9615-4.

\section{E. Fadul}

Neuro-Oncology Program, Norris Cotton Cancer Center, Dartmouth Hitchcock Medical Center, Dartmouth Medical

School, Lebanon, NH, USA

P. Y. Wen

Center for Neuro-Oncology, Dana Farber/Brigham and Women's Cancer Center and Department of Neurology, Brigham and Women's Hospital, Boston, MA, USA

\section{Kim}

Neuro-oncology Branch, NCI, National Institutes of Health, Bethesda, MD, USA

\section{J. J. Olson $(\square)$}

Department of Neurosurgery, Emory University School of Medicine, 1365B Clifton Rd., NE, Ste. 6200, Atlanta, GA 30322, USA

e-mail: jeffrey.olson@emoryhealthcare.org 